\title{
Síndrome de Gorlin Goltz: relato de um caso raro com extenso ceratocisto comprimindo nervo óptico
}

\author{
Gorlin Goltz syndrome: a case report of a rare case with extensive ceratocyst compressing optic
} nerve

\section{Síndrome de Gorlin Goltz: reporte de un caso raro con queratoquiste extenso comprimiendo el nervio óptico}

Ciro Borges Duailibe de Deus

ORCID: https://orcid.org/0000-0001-9684-6956 Universidade Estadual Paulista “Júlio de Mesquita Filho", Brasil Universidade Estácio de Sá, Brasil Faculdade Pitágoras, Brasil

E-mail: ciro_duailibe@hotmail.com

João Victor Uchôa Silva

ORCID: https://orcid.org/0000-0003-0840-5902 Faculdade Pitágoras, Brasil

E-mail: joaovictorneto10@hotmail.com

André Hergesel de Oliva

ORCID: https://orcid.org/0000-0001-5818-9350 Universidade Estadual Paulista "Júlio de Mesquita Filho", Brasil E-mail: holivaandre@gmail.com

William Phillip Pereira da Silva

ORCID: https://orcid.org/0000-0003-4172-7217

Universidade Estadual Paulista "Júlio de Mesquita Filho", Brasil

E-mail: william_phillip@hotmail.com

Anderson Maikon de Souza Santos

ORCID: https://orcid.org/0000-0001-9371-9417

Universidade Estadual Paulista "Júlio de Mesquita Filho", Brasil

E-mail: andersonmaikon@ hotmail.com

Tiburtino José de Lima Neto

ORCID: https://orcid.org/0000-0002-8297-4057

Universidade Estadual Paulista "Júlio de Mesquita Filho", Brasil

E-mail: tiburtinoneto@hotmail.com

Francisley Ávila Souza

ORCID: https://orcid.org/0000-0002-1427-071X

Universidade Estadual Paulista “Júlio de Mesquita Filho", Brasil

E-mail: francisley.avila@unesp.br

\begin{abstract}
Resumo
A síndrome de Gorlin Goltz é uma condição genética autossômica dominante e rara, que acomete diversos órgãos e sistemas, podendo ser identificados carcinomas basocelulares, ceratocistos odontogênicos, anomalias estruturais ósseas e neurológicas. O objetivo deste trabalho é elucidar os principais critérios para o correto diagnóstico e expor um caso clínico cirúrgico. Paciente do gênero masculino, 14 anos, leucoderma, apresentou-se com queixa de intensa cefaleia e déficit visual. O exame físico revelou aumento do diâmetro torácico, implantação baixa das orelhas, hipertelorismo e assimetria de face ao lado esquerdo. As tomografias de face e crânio revelaram calcificação da foice cerebral e lesões múltiplas nos ossos gnáticos. Na tomografia de tórax observou-se costela bífida e cifoescoliose. $\mathrm{O}$ paciente foi avaliado pela equipe de oftalmologia, que concluiu que o déficit visual ocorria devido à compressão do nervo óptico causado pela lesão de grandes proporções na maxila. Foi então planejada e realizada a cirurgia de descompressão da lesão maxilar e enucleação das lesões mandibulares, que, através da histopatologia, confirmou-se tratar de ceratocistos múltiplos, definindo assim o diagnóstico de síndrome de Gorlin Goltz através da identificação de vários critérios pertinentes, segundo Kimonis et al., 1997. No período pós-cirúrgico, o paciente apresentou remissão total das queixas de cefaleia e déficit visual. A síndrome de Gorlin Goltz, pode evoluir rapidamente com consequências nocivas para diferentes órgãos, mesmo nos pacientes jovens, o que reforça a importância do diagnóstico precoce e abordagem multiprofissional.
\end{abstract}

Palavras-chave: Síndrome de Gorlin Goltz; Carcinoma basocelular; Ceratocistos odontogênicos. 


\begin{abstract}
Gorlin Goltz syndrome is a rare and autosomal dominant genetic condition that affects several organs and systems, and basal cell carcinomas, odontogenic keratocysts, bone and neurological structural abnormalities can be identified. The objective of this work is to elucidate the main criteria for the correct diagnosis and to expose a surgical clinical case. Male patient, 14 years old, leucoderma, presented with a complaint of severe headache and visual impairment. The physical examination revealed an increase in chest diameter, low implantation of the ears, hypertelorism and asymmetry of the face on the left side. The face and skull tomography revealed calcification of the falx cerebri and multiple lesions in the gnathic bones. On chest tomography, rib bifida and kyphoscoliosis were observed. The patient was evaluated by the ophthalmology team, who concluded that the visual deficit was due to the compression of the optic nerve by a large lesion in the maxilla. It was then planned and performed the decompression surgery of the maxillary lesion and enucleation of the mandibular lesions, which, through histopathology, confirmed that it was multiple keratocysts, thus defining the diagnosis of Gorlin Goltz syndrome through the identification of several criteria relevant according to Kimonis et al., 1997. In the post-surgical period, the patient had a complete remission of complaints of headache and visual impairment. Gorlin Goltz syndrome can evolve rapidly with harmful consequences for different organs, even in youngs patients, which reinforces the importance of early diagnosis and a multidisciplinary approach.
\end{abstract}

Keywords: Gorlin-Goltz syndrome; Carcinoma basal cell; Odontogenic keratocysts.

\title{
Resumen
}

El síndrome de Gorlin Goltz es una condición genética rara y autosómica dominante que afecta a varios órganos y sistemas, pudiendo identificarse carcinomas de células basales, queratoquistes, anomalías estructurales óseas y neurológicas. El objetivo de este trabajo es dilucidar los principales criterios para el correcto diagnóstico y exponer un caso clínico quirúrgico. Paciente masculino de 14 años, leucodermia, que consulta por cefalea intensa y discapacidad visual. El examen físico reveló aumento del diámetro torácico, baja implantación de las orejas, hipertelorismo y asimetría de la cara del lado izquierdo. La tomografía de rostro y cráneo reveló calcificación de la hoz cerebral y múltiples lesiones en los huesos gnáticos. En la tomografía de tórax se observó costilla bífida y cifoescoliosis. El paciente fue evaluado por el equipo de oftalmología, quien concluyó que el déficit visual se debía a la compresión del nervio óptico por una gran lesión en el maxilar. Posteriormente se planificó y realizó la cirugía de descompresión de la lesión maxilar y enucleación de las lesiones mandibulares, que mediante histopatología confirmó que se trataba de queratoquistes múltiples, definiendo así el diagnóstico de síndrome de Gorlin Goltz mediante la identificación de varios criterios relevantes según Kimonis et al., 1997. En el período posquirúrgico, el paciente tuvo una remisión completa de las quejas de dolor de cabeza y discapacidad visual. El síndrome de Gorlin Goltz puede evolucionar rápidamente con consecuencias perjudiciales para diferentes órganos, mismo en pacientes jóvenes, lo que refuerza la importancia del diagnóstico precoz y de un abordaje multidisciplinar.

Palabras clave: Síndrome de Gorlin Goltz; Carcinoma basocelular; Queratoquistes odontogénicos.

\section{Introdução}

A síndrome de Gorlin Goltz (SGG) ou síndrome do Carcinoma Basocelular Nevóide, é um acometimento raro, de caráter autossômico dominante e está relacionada a efeitos deletérios no cromossomo 9q22.3, afetando assim, o gene PTCH-1, um gene supressor tumoral envolvido na regulação da via Hedgehog para diferenciação celular, podendo ainda ser relatados à esta síndrome mutações de outros genes como PTCH-2, SUFU e SMO. (Cesinaro, Burtini, Maiorana, Rossi, \& Migaldi, 2020; Gao, Xu, Yang, Yang, \& Bian, 2020).

A SGG foi primeiramente relatada por Jarisch e White em 1894, e, no ano de 1960, a síndrome foi delineada e aceita como entidade distinta após a definição realizada por Robert J. Gorlin e Robert W. Goltz (Gorlin \& Goltz, 1960; Jarisch, 1894).

Esta enfermidade apresenta alta penetrância e uma expressividade variável, sendo as características mais comuns: carcinomas basocelulares, múltiplos ceratocistos odontogênicos e variadas anormalidades de desenvolvimento (González González, Matilla Fernández, Ferreras López, Nieto Mangudo, \& Ortiz de Urbina González, 2020).

De forma geral, o diagnóstico é baseado em um padrão de critérios inicialmente estabelecido por Evans et al., em 1993 e reformado posteriormente por Kimonis et al., em 1997. (Evans et al., 1993; Kimonis et al., 1997). Os critérios de diagnóstico são classificados em principais e secundários, sendo que, para que haja confirmação diagnóstica, o paciente deverá apresentar dois critérios principais, ou, um principal e dois critérios secundários (Kimonis et al., 1997). Como forma de 
confirmação absoluta, pode ser realizado ainda o teste genético para evidenciar mutação no gene PTCH-1 (Sánchez Linares et al., 2018; Tomasso, Assi, \& Nguyen, 2020).

O objetivo deste trabalho é esclarecer as características comuns da SGG para um diagnóstico precoce e preciso, expondo um caso clínico cirúrgico de um paciente tratado através de descompressão e enucleação de ceratocistos múltiplos nos maxilares.

\section{Metodologia}

O presente estudo se trata de um relato de caso clínico cirúrgico, que consiste em um tipo de estudo descritivo e retrospectivo, realizado por meio da técnica de observação direta e revisão de literatura sobre o tema através de artigos encontrados nas bases de dados SCIELO (Scientific Eletronic Library On-line), PubMed, Science Direct e Google Acadêmico. A responsável pela paciente autorizou a divulgação dos dados e exibição das imagens por meio de assinatura de Termo de Consentimento Livre e Esclarecido (TCLE), respeitando todos os princípios éticos da Declaração de Helsinque.

\section{Relato de Caso}

Paciente do gênero masculino, L.P.P., 14 anos, leucoderma, cursando com episódios de cefaleia intensa, dores faciais, incômodo visual (vista embaçada) e tumefação em hemiface lado esquerdo (Figuras 1A, B e C), foi encaminhado para o Hospital Santa Casa de Misericórdia de Araçatuba/SP para avaliação com o serviço de Cirurgia e Traumatologia Buco-MaxiloFacial.

Figuras 1. Imagens clínicas.

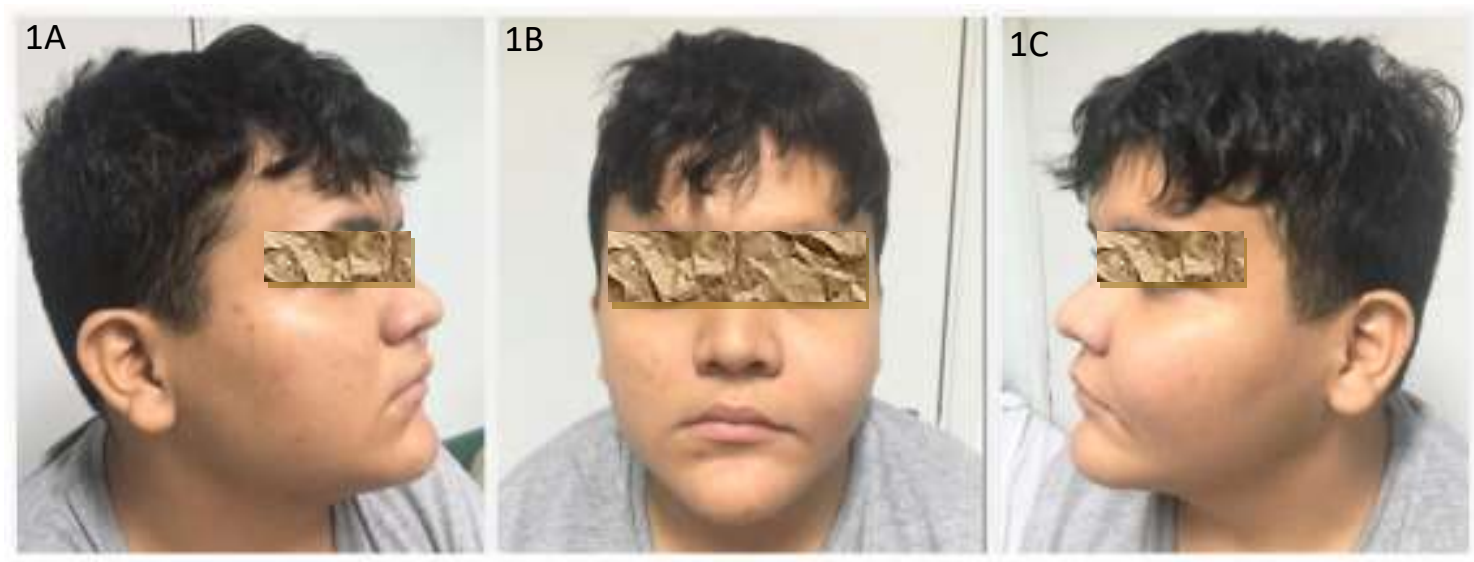

Fonte: Departamento de Cirurgia e Clínica Integrada da Faculdade de Odontologia de Araçatuba (2021).

Durante a anamnese, a responsável relatou ainda que o paciente não possuía, até aquele momento, doenças sistêmicas ou alergias medicamentosas, porém, apresentava déficit de atenção e que seu irmão tinha estrutura corporal semelhante.

Durante o exame físico geral, o paciente apresentava alterações em sua constituição, como: tórax com formato amplo e projetado (Pectus carinatum), cifose, escoliose, deformidade de Sprengel, proeminência frontal acentuada (bossa frontal), mandíbula e cristas supraorbitais proeminentes, circunferência da cabeça aumentada, hipertelorismo, ponte nasal larga e implantação baixa das orelhas. 
Durante o exame extraoral, foi notado tumefação difusa em região do lado esquerdo da face, de formato oval, envolvendo toda a região vestibular maxilar. A pele sobre a região se apresentava lisa, com margens bem definidas e com coloração característica de normalidade. À palpação, o edema apresentava consistência firme e sensível. Este crescimento tecidual não apresentava temperatura aumentada e nem mobilidade. $\mathrm{O}$ paciente apresenta sua cadeia ganglionar com aspecto de normalidade, sem linfonodos palpáveis ou infartados.

Durante o exame intraoral foi notado uma tumefação solitária difusa em região de vestíbulo maxilar esquerdo relacionado aos dentes 25, 26 e 27, de dimensões aproximadas de 40 x 30mm, o que obliterava o vestíbulo e se estendia tanto no sentido anteroposterior, quanto, no sentido ínfero superior. A mucosa sobre a lesão se apresentava com coloração discretamente eritematosa e com características de normalidade em sua periferia. Através da palpação direta do edema, notouse consistência macia, flácida, compressível, sem drenagem de secreção, com margens mal definidas.

Foi solicitado tomografia computadorizada de face (TCF), de crânio (TCC), de tórax (TCT) e avaliação com a oftalmologia. Durante o exame de TCF, foi notada extensa lesão em região de seio maxilar esquerdo, ocupando todo o antro, se estendendo no sentido ínfero-superior do assoalho maxilar até o assoalho orbital (Figuras 2A e F), em sentido látero-medial causava expansão importante da região vestibular maxilar e penetrava ainda em região nasal (Figuras $2 \mathrm{~B}$ e F), e, em sentido ântero-posterior, acometia toda a região anterior e posterior do seio maxilar (Figuras $2 \mathrm{C}$ e F). Foram encontradas ainda três lesões em mandíbula, sendo duas na região anterior (Figura 2D) e uma na região posterior direita (Figura 2E).

Figuras 2. Imagens tomográficas de face.
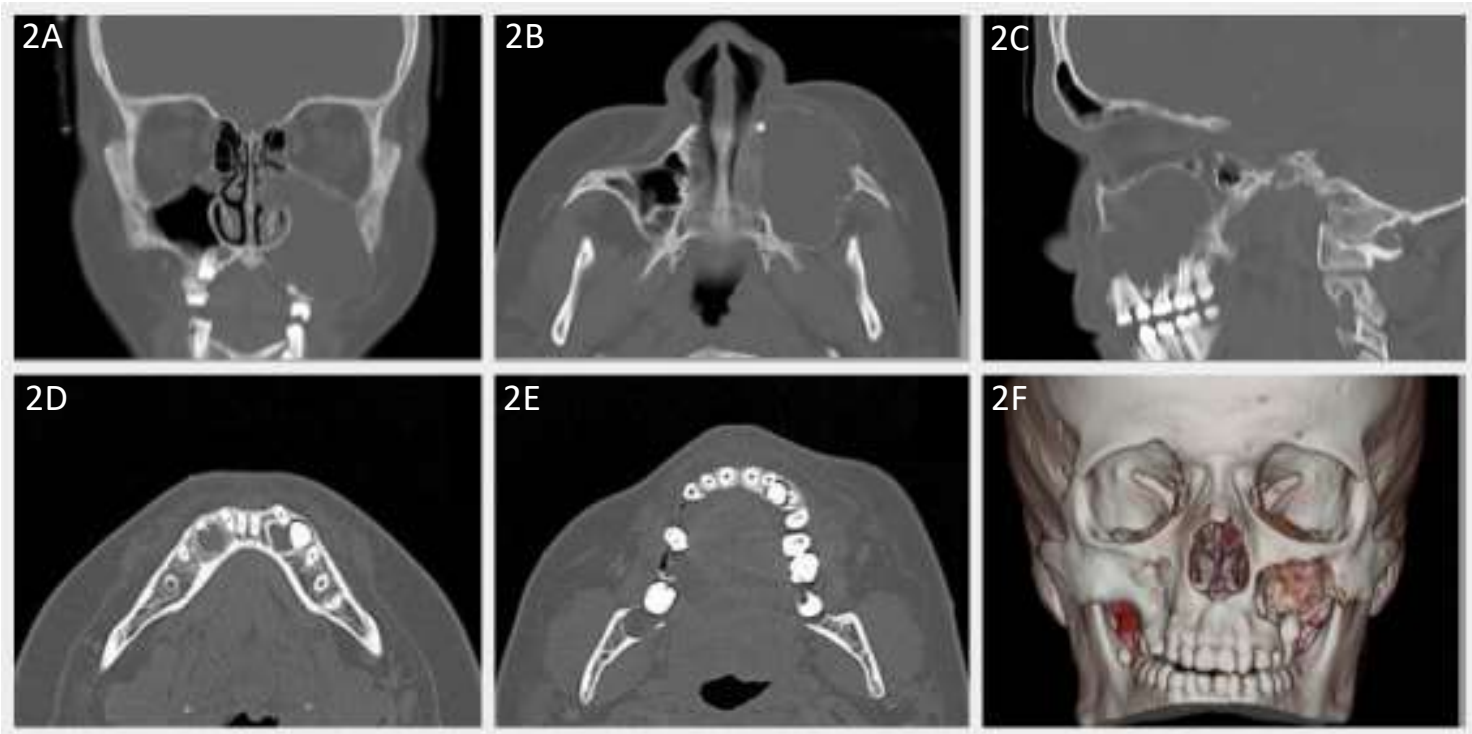

Fonte: Departamento de Cirurgia e Clínica Integrada da Faculdade de Odontologia de Araçatuba (2021).

Durante o exame de TCC e TCT foram encontradas calcificações da foice cerebral (Figura 3A), costela bífida (Figura 3B) e confirmado por imagem tomográfica a cifoescoliose (Figura 3C). O oftalmologista ao realizar sua avaliação, relatou que o incomodo visual estava intimamente ligado à compressão da órbita causada pela expansão desta lesão maxilar e sugeriu o seu tratamento cirúrgico. 
Figuras 3. Imagens tomográficas de crânio e tórax.
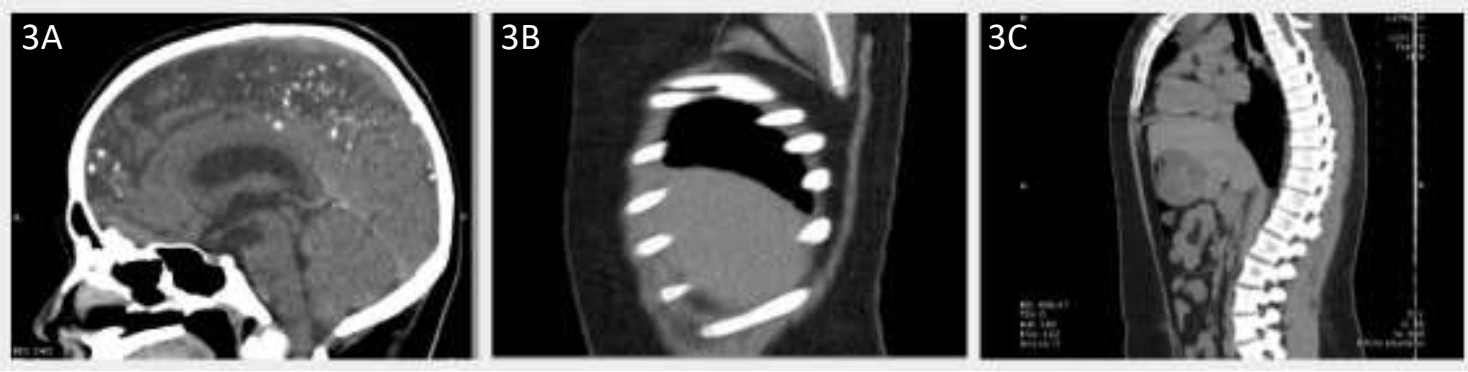

Fonte: Departamento de Cirurgia e Clínica Integrada da Faculdade de Odontologia de Araçatuba (2021).

Foi então programado para equipe de Cirurgia e Traumatologia Buco-Maxilo-Facial a intervenção cirúrgica sob anestesia geral. A cirurgia foi iniciada com a realização de aspiração de todas as lojas, sendo obtido como conteúdo intraluminal substância pastosa de coloração amarelada compatível com sustância queratinoza (Figura 4A). Foi então realizado a técnica de descompressão com dispositivo da lesão maxilar, e, enucleação seguida de curetagem das lesões mandibulares. Foi utilizado neste caso por suas características de fácil manuseio e adaptação, uma chupeta de bebê estéril, que foi devidamente reduzida para a correta acomodação e manutenção de via pérvia para a limpeza, com o intuito de evitar a progressão expansiva e favorecer a sua redução para enucleação total futura (Figura 4B). A chupeta adaptada foi mantida no local através de suturas (Figuras 4C e D), e, para os três cistos menores, foi decidido a realização de enucleação total, seguido de aplicação de solução de Carnoy para debridamento de possíveis remanescentes que poderiam evoluir para novas lesões no futuro, tanta nas lesões mandibulares anteriores (Figura 4E), quanto na lesão mandibular posterior (Figura 4F). As amostras teciduais foram devidamente acondicionadas em frascos individualizados e identificados com formol 10\%, para o envio para o laboratório de histopatologia.

Figuras 4. Procedimento cirúrgico.
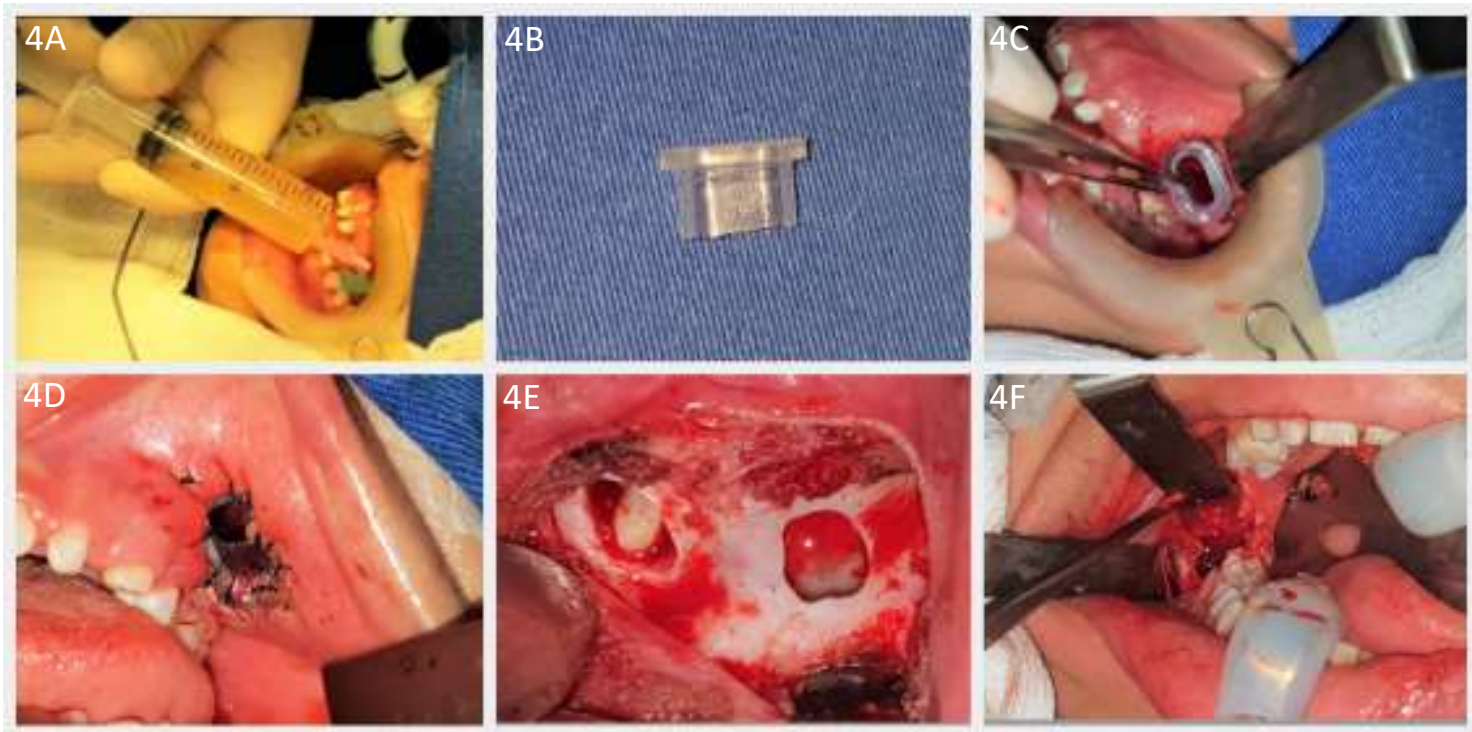

Fonte: Departamento de Cirurgia e Clínica Integrada da Faculdade de Odontologia de Araçatuba (2021).

O laudo histopatológico definitivo foi de ceratocisto odontogênico para as quatro lesões, o que confirmou, a partir de todo compilado envolvendo o histórico do paciente, anamnese, exame físico, exame extra e intraoral, quando confrontados 
com os critérios de Kimonis et al., o diagnóstico de Síndrome de Gorlin Goltz. Fica evidente na tomografia pós operatória imediata o sucesso do esvaziamento intraluminal e o correto posicionamento do dispositivo de descompressão, comunicando o meio intraoral com o interior do seio maxilar (Figura 5).

Figura 5. Tomografia computadorizada de face pós operatória.

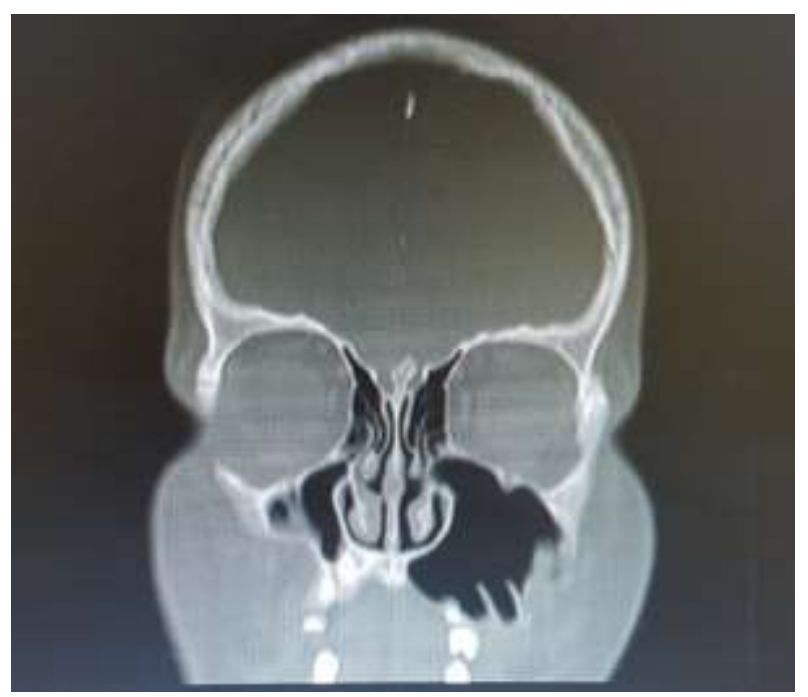

Fonte: Departamento de Cirurgia e Clínica Integrada da Faculdade de Odontologia de Araçatuba (2021)

O paciente se encontra em período de acompanhamento de seis meses, não relatando desconforto visual ou sintomatologia dolorosa, sendo evidenciado tomograficamente nas regiões abordadas, imagem radiolúcida para o seio maxilar, e, imagens bem definidas com halo radiopaco com sinais de regressão dimensional das lesões mandibulares, compatíveis com características imaginológicas de neoformação óssea.

\section{Discussão}

A SGG é uma doença rara, com caráter hereditário autossômico dominante com acometimento multissistêmico, penetrância completa e expressividade variável (Tomasso et al., 2020). O primeiro relato da SGG na literatura foi realizado por Jarisch e White em 1894, em um paciente que cursava com múltiplos carcinomas basocelulares, escoliose e dificuldade de aprendizado (Jarisch, 1894; Narang, Maheshwari, Aggarwal, Bansal, \& Singh, 2020). Posteriormente, em 1960, esta entidade foi descoberta e pormenorizadamente descrita por Robert J. Gorlin e Robert W. Goltz, que a descreveram como uma síndrome distinta, consistindo na presença de múltiplos epiteliomas de células basais nevóides, lesões císticas nos maxilares e costelas bífidas, dando origem ao nome da síndrome (Gorlin \& Goltz, 1960; MDS \& MDS, 2020).

A SGG ou síndrome do carcinoma basocelular nevóide, também é conhecida por síndrome da costela bífida, síndrome do nevo basocelular e quinta facomatose (Lata \& Kaur, 2020). Esta doença se manifesta através de alterações múltiplas no corpo, envolvendo a pele, olhos, ossos, sistema nervoso e endócrino. As manifestações clínicas da síndrome são manifestações cutâneas: calcinose dérmica, cistos e tumores dérmicos benignos, corrosão palmar, nevo basocelular, ceratose palmar e plantar; manifestações dentárias e ósseas: prognatismo mandibular leve, protuberância frontal e temporoparietal, cifoescoliose, costelas e espinha bífida, ceratocistos múltiplos e lábio leporino; manifestações oftálmicas: hipertelorismo, ponte nasal larga, cegueira congênita e estrabismo interno; manifestações neurológicas: retardo mental, calcificação dural e da foice cerebral, obstrução da sela túrcica, agenesia do corpo caloso, hidrocefalia congênita e meduloblastoma; anomalias sexuais: hipogonadismo e fibrossarcoma semelhante a tumor ovariano (MDS \& MDS, 2020). 
É estimado uma prevalência de acometimento que gira em torno de 1/57.000 a 1/256.000, sem predisposição para um dos gêneros sexuais (Gao et al., 2020; MDS \& MDS, 2020; Narang et al., 2020). A mandíbula demonstra uma propensão maior de acometimento de 3:1 quando comparada à maxila (MDS \& MDS, 2020). Tem como origem os restos epiteliais da lâmina dental, sendo frequentemente detectada em pacientes leucodermas na segunda e terceira década de vida (Narang et al., 2020; Sánchez Linares et al., 2018).

Mutações no gene supressor tumoral PTCH-1, localizado no cromossomo 9q22.3, produzem um desequilíbrio importante e estão fortemente relacionadas como a origem da síndrome, pois, resultam em redução de atividade da proteína PTCH, um receptor transmembrana para a proteína Sonic Hedgehog. Esta função alterada é fortemente associada às alterações encontradas nos critérios detalhados por Kimonis e colaboradores, que envolve danos na embriogênese, formação do sistema nervoso central e padrão neural, enquanto alterações em genes PTCH-2 e SUFU-1 são comumente menos encontrados em pacientes portadores de SGG (Gao et al., 2020; Gutiérrez Patiño-Paul \& Rivadeneyra Rodriguez, 2020; Osiecka, Nockowski, \& Szepietowski, 2020; Tomasso et al., 2020).

O diagnóstico é baseado nas características mais evidentes e específicas da síndrome, conforme os critérios preconizados por Evans et al e modificados por Kimonis et al., os critérios utilizados para diagnóstico são subdivididos em principais e secundários. Para diagnosticar a SGG é necessário identificar no paciente dois critérios principais, ou, um critério principal e dois critérios secundários (Evans et al., 1993; Gao et al., 2020; Gutiérrez Patiño-Paul \& Rivadeneyra Rodriguez, 2020; Jain, Rathod, Gandhi, \& Ghai, 2020; Khaliq et al., 2016; Kimonis et al., 1997; Lata \& Kaur, 2020; MDS \& MDS, 2020; Narang et al., 2020; Osiecka et al., 2020; Sánchez Linares et al., 2018). No paciente exposto nesse trabalho, o diagnóstico de SGG foi determinado após ser identificado a presença de três critérios principais e cinco critérios secundários, como pode ser visto destacado em negrito no Quadro 1.

O diagnóstico precoce pode alertar os pacientes afetados para um acompanhamento mais preciso, podendo assim evitar ocorrências ou recorrências de lesões cancerígenas, e para também tratar várias outras anormalidades associadas. Pacientes jovens são mais suscetíveis a neoplasias múltiplas, por isso, se mostra indispensável o comprometimento com o entendimento e diagnóstico desta patologia, devendo ainda evitar radiação ultravioleta, pois o aumento de exposição está intimamente relacionado ao aparecimento de carcinomas de pele nesses casos. Após o diagnóstico bem estabelecido, o tratamento visa abordagem multidisciplinar envolvendo monitoramento constante da pele, e detecção de possíveis alterações ósseas. (Narang et al., 2020). 
Quadro 1. Critérios de diagnóstico.

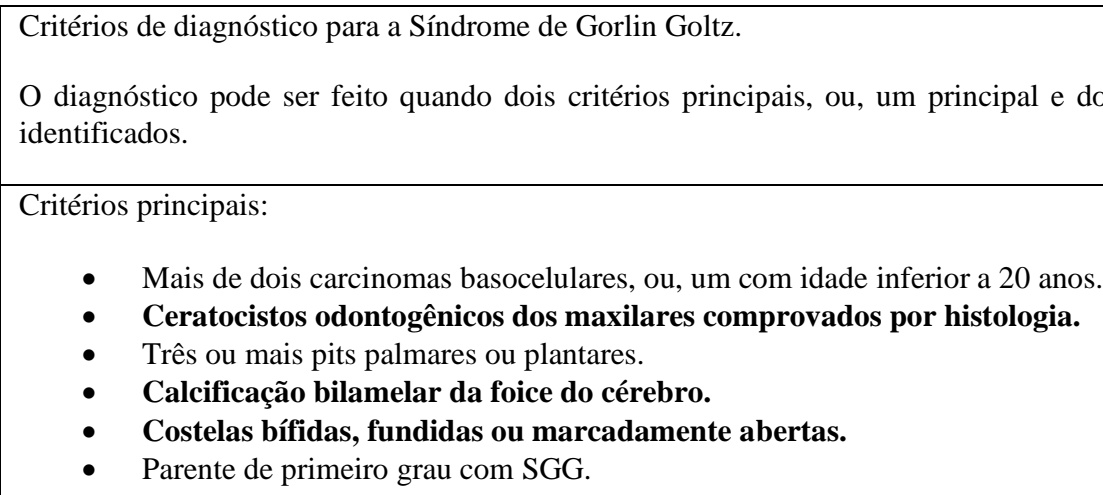

Critérios secundários:

- Macrocefalia determinada após ajuste para altura.

- Malformações congênitas: lábio leporino ou palato, bossa frontal, "face áspera", hipertelorismo moderado ou grave.

- Outras anormalidades esqueléticas: deformidade de Sprengel, deformidade torácica acentuada (Pectus carinatum ou excavatum), sindactilia acentuada dos dedos.

- Anormalidades radiológicas: pontificação da sela túrcica, anomalias vertebrais como hemivértebras, fusão ou alongamento dos corpos vertebrais, defeitos de modelagem das mãos e pés e lucências em forma de chama nas mãos ou pés.

- Fibroma ovariano.

- Meduloblastoma.

Fonte: (Kimonis et al., 1997).

\section{Conclusão}

O diagnóstico precoce da síndrome é essencial para que seja possível evitar a progressão da doença. É muito importante reconhecer os critérios principais e secundários para que seja contido o seu potencial maligno. Para o diagnóstico precoce, é necessário realizar um compilado de exames e avaliações multidisciplinares envolvendo as especialidades: cirurgia e traumatologia buco-maxilo-facial, cirurgia de cabeça e pescoço, patologia, oftalmologia, dermatologia, neurologia, pediatria e genética, para que a condução do caso seja realizada de forma satisfatória. Em relação ao seu caráter hereditário autossômico dominante, se mostra necessário o acompanhamento e aconselhamento genético dos pais, filhos e irmãos do portador da SGG, para que seja rastreada qualquer alteração definida como critério específico para a doença, evitando assim, desmembramentos malignos. O tratamento cirúrgico envolve exérese de carcinomas, descompressão e curetagem dos ceratocistos, além disso, o paciente deve ser incluído em um cronograma para acompanhamento regular, rigoroso e prolongado, para que assim evite recidivas e tenha melhor qualidade de vida.

\section{Referências}

Cesinaro, A. M., Burtini, G., Maiorana, A., Rossi, G., \& Migaldi, M. (2020). Expression of calretinin in odontogenic keratocysts and basal cell carcinomas: A study of sporadic and Gorlin-Goltz syndrome-related cases. Ann Diagn Pathol, 45, 151472. doi:10.1016/j.anndiagpath.2020.151472

Evans, D. G., Ladusans, E. J., Rimmer, S., Burnell, L. D., Thakker, N., \& Farndon, P. A. (1993). Complications of the naevoid basal cell carcinoma syndrome: results of a population based study. J Med Genet, 30(6), 460-464. 10.1136/jmg.30.6.460

Gao, Q., Xu, N., Yang, C., Yang, K., \& Bian, Z. (2020). Novel PTCH1 mutation in Gorlin-Goltz syndrome potentially altered interactions with lipid bilayer. Oral Dis. 10.1111/odi.13586

González González, M. A., Matilla Fernández, M. B., Ferreras López, N., Nieto Mangudo, B., \& Ortiz de Urbina González, J. J. (2020). Tratamiento y descanso terapéutico con vismodegib en un paciente con síndrome de Gorlin Goltz. Piel, 35(1), 22-24. https://doi.org/10.1016/j.piel.2018.11.014

Gorlin, R. J., \& Goltz, R. W. (1960). Multiple nevoid basal-cell epithelioma, jaw cysts and bifid rib. A syndrome. $N$ Engl J Med, 262, 908-912. $10.1056 /$ nejm196005052621803 
Research, Society and Development, v. 10, n. 2, e9410212315, 2021

(CC BY 4.0) | ISSN 2525-3409 | DOI: http://dx.doi.org/10.33448/rsd-v10i2.12315

Gutiérrez Patiño-Paul, A., \& Rivadeneyra Rodriguez, A. (2020). Queratoquiste odontogenico recurrente en paciente con sindrome de Gorlin-Goltz \%J Revista Estomatológica Herediana. 30, 53-62.

Jain, N. A., Rathod, V. J., Gandhi, M. S., \& Ghai, A. P. J. I. J. o. R. i. M. S. (2020). Gorlin Goltz syndrome: a rare case report. 8(7), 1.

Jarisch, W. J. A. D. S. (1894). Zur lehre von den hautgeschwulsten. 28, 163-222.

Khaliq, M. I. U., Shah, A. A., Ahmad, I., Hasan, S., Jangam, S. S., Farah, \& Anwar. (2016). Keratocystic odontogenic tumors related to Gorlin-Goltz syndrome: A clinicopathological study. Journal of Oral Biology and Craniofacial Research, 6(2), 93-100.https://doi.org/10.1016/j.jobcr.2015.09.002

Kimonis, V. E., Goldstein, A. M., Pastakia, B., Yang, M. L., Kase, R., DiGiovanna, J. J., \& Bale, S. J. (1997). Clinical manifestations in 105 persons with nevoid basal cell carcinoma syndrome. 69(3), 299-308. https://doi.org/10.1002/(SICI)1096-8628(19970331)69:3<299::AID-AJMG16>3.0.CO;2-M

Lata, J., \& Kaur, J. (2020). A unique case of Gorlin\&\#8211;Goltz syndrome with associated Sotos syndrome. 10(1), 232-237. 10.4103/ams.ams_91_19

MDS, D. N. A., \& MDS, D. S. N. (2020). Gorlin Goltz Syndrome -A Case Series \%J European Journal of Molecular \& Clinical Medicine. 7(4), $1452-1458$.

Narang, A., Maheshwari, C., Aggarwal, V., Bansal, P., \& Singh, P. (2020). Gorlin-Goltz Syndrome with Intracranial Meningioma: Case Report and Review of Literature. World Neurosurgery, 133, 324-330. https://doi.org/10.1016/j.wneu.2019.09.156

Osiecka, B. J., Nockowski, P., \& Szepietowski, J. C. (2020). The use of the photodynamic method in the treatment of recurrent basal cell carcinoma on the example of Gorlin-Goltz syndrome-management algorithm. 33(6), e14499. https://doi.org/10.1111/dth.14499

Sánchez Linares, V., Rodríguez Montagne, D., Cifuentes Suárez, J. P., Román Simón, M., Pérez Garcia, C., \& Bello Rivero, I. (2018). Síndrome de Gorlin Goltz. A propósito de un caso \%J Gaceta Médica Espirituana. 20, 136-145.

Tomasso, D., Assi, E. B., \& Nguyen, D. K. (2020). Gorlin-Goltz syndrome and epilepsy: A two-case report and review of the literature. Epilepsy Behav Rep, 14, 100384. 10.1016/j.ebr.2020.100384 